\title{
Proficient Prophecy of Foreign Exchange Rate using Artificial Neural Network: A Case of USD to INR
}

\author{
Suresh Kumar Sharma \\ Department of Computer Science and IT \\ University of Jammu
}

\author{
Vinod Sharma \\ Department of Computer Science and IT \\ University of Jammu
}

\begin{abstract}
The value of foreign exchange rate has vital role in today's global market. Know even the approximate value of the exchange rate a day before helps the businessman to plan their investments. In this research paper popular machine learning technique artificial neural network with back propagation is used for predicting the value of exchange rate value of USD in term of Indian Rupees. The inputs for neural network are prepared using moving average technique. The experimental setup is designed and implemented in MATLAB. The interesting results so obtained are shown in this paper.
\end{abstract}

\section{General Terms}

Exchange Rate, Forecasting, Artificial Neural Network.

\section{Keywords}

Moving Average, Mean Absolute Error, Mean Square Error, USD, INR

\section{INTRODUCTION}

The crucial processing component of artificial neural network is called neuron. It is a highly interconnected network of neurons. ANN exhibits parallel distributed processing. The main trait of ANN is that it learns by known examples of a problem to obtain knowledge about it. This is known as training for ANN. After trained successfully the network can be put to effective use in solving anonymous or untrained instances of the problem [1]. Exchange rate forecasts are drawn up through the computation of a currency's value vis-àvis other currencies over a period of time. In today's international market, exactness in forecasting or at least prediction the trend of foreign rate exchange exactly is of crucial importance for any future investment. Future movement of foreign exchange can be obtained by studying the series of past price [2]. The amount of international trade has experienced unique growth over the past few decades. This increase in global operation and interactions has propelled the foreign exchange market to be the largest and most liquid of the financial markets. The complex interaction of varied factors from both the private and public sectors and on a macro and micro economics levels makes exchange rate prediction one of the most challenging amongst time series forecasting. There are already various mathematical and statistical techniques for predicting foreign rate exchange. But mathematical approaches demand a high degree of precision and accuracy in their requirements. But in most engineering problems the input parameters cannot be determined with a high degree of precision and therefore we go for Artificial Neural Network which is also deal with missing data. While there are various theories that can be used to predict exchange rates, all of them have limitations. No model has been able to establish a monopoly in the forecasting process. As it is possible to model both linear and nonlinear structures in time series by using Artificial Neural Network (ANN), it is suitable to apply this method to the chaotic series having nonlinear component [3].

\section{REVIEW OF LITERATURE}

Forecasting is a key process to the efficient operation in any field. Now a day researchers are trying a variety of machine learning models for prediction in industries. Artificial Neural Network (ANN) has been increasingly recognized as a good forecasting tool in various fields. Review literature analyses identified various fields and nature of forecasting where ANN is used or using most extensively.

\subsection{Gas Load Forecasting Through Ann}

Gas load prediction aids the corporation to make essential conclusions including decision on buying and selling gas cylinders, loading of gas cylinder, and infrastructure development. The main goal of this paper is to construct an experimental setup that forecast the number of cylinder requirement on next 24 hours. The important variables that researchers are going to consider in this experimental setup are related to weather conditions i.e. minimum and maximum temperature, the previous days load value and the nature of that day i.e. holiday or not. These input variables are fed into the network based on Multilayer Artificial Neural Network with back-propagation. The output of this network helps gas industry to anticipate the amount of gas cylinders needed to supply the demand. The network used in this experiment has 12 hidden layers. The real data set about 2 months from a gas industry is used to train the ANN learning algorithm [4].

\subsection{Gross Domestic Product Forecasting and $A N N$.}

Gross Domestic Product (GDP) is a benchmark for economic production conditions of a country. ANN can mimic the workings of the human brain makes it flexible for non-linear and non-parametric data. Results from this study indicate that ANN forecasts GDP relatively better than the one issued by the government. Further study would be to use ANN to predict other economic indicators [5].

\subsection{Short-Term Electricity Load} Forecasting with ANN.

In this paper researchers present an accurate electricity load forecasting algorithm with back propagation neural networks. It contributes to short-term electricity load forecast methodology with neural network with weather feature such as max centigrade, min centigrade and weather types. The original electricity load is from shanghai district, which is composed of original every 5 minutes load records. Through the data transform the every hour data average 12 original records and weather feature become double value. After training and simulation, the prediction errors fit for the 
application needs. The algorithm besides other algorithms has been used in electricity load forecasting software. Many results confirm that the proposed method is capable of forecasting load efficiently [6].

\section{FORECASTING THROUGH COMPUTER}

Machine learning is an innovative method that can potentially improve forecasting models and assist management decision making. Machine learning refers to computer-based method that can extract pattern or knowledge from data and perform optimization task with minimum human intervention. Most of these methods have their roots in artificial intelligence and dynamic programming. In short we can say that machine learning algorithms learns from data. Data mining is used to extracting patterns from data and machine learning used extracted pattern to do prediction. In computer science, when a system. Forecasting through computer has some limitations. These are:

(i) Forecasting is based on future events which are not sure to exist. Thus forecasting cannot be accurate

(ii) Forecasting models are mathematical and statistical in nature. These methods cannot claim to be able to make uncertain future certain.

(iii) Forecasting cannot guarantee the elimination of errors and mistakes.

(iv) Factors responsible for economic changes are often difficult to discover and to measure.

(v) The business forecasting does not evaluate risks [7][8][9].

\section{DATA SET AND METHODOLOGY}

In this model, the data set is obtained online from the website (http://www.x-rates.com/d/INR/USD/data120 .html) for the period 120 days for training purpose. Further 11 days data for testing purpose. Here moving average value of past weeks to feed to the neural network to predict the following week's rate. The indicators are MA1W, MA2W, MA1M, MA1Q, MAHY and $\mathrm{Xi}$, namely moving average of one week, two week, one month, one quarter, half yearly and last week closing rate respectively. Thus the neural network has six inputs and one output unit to predict exchange rate. In this research paper we use Back propagation learning algorithm to train the artificial neural network [10][11][12][13][14]. After training the ANN is able to forecasting exchange rate value of next day. The activation function used in this research paper for training ANN is Sigmoidal. The experimental setup for the Back propagation learning algorithm is constructed.

\section{MEASUREMENT CRITERIA [10] [11] [12] [14].}

\begin{tabular}{|c|c|c|}
\hline Criteria & Mathematical Equation & Remarks \\
\hline $\begin{array}{l}\text { Normalized } \\
\text { Mean Square } \\
\text { Error } \\
\text { (NMSE) }\end{array}$ & 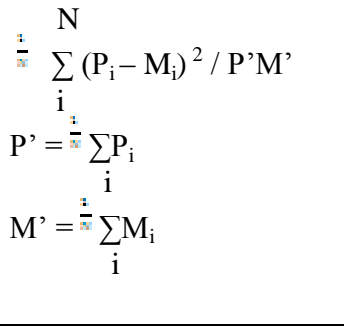 & $\begin{array}{l}\text { Estimator of the } \\
\text { overall } \\
\text { deviations } \\
\text { between } \\
\text { predicted and } \\
\text { measured value }\end{array}$ \\
\hline $\begin{array}{l}\text { Mean } \\
\text { Absolute } \\
\text { Error (MAE) }\end{array}$ & $\begin{array}{l}n=f_{i}^{n}\left|f_{i}-y_{i}\right|=\frac{\sum_{i}}{\sum}\left|e_{i}\right| \\
\text { fi : the prediction } \\
\text { yi : True Value }\end{array}$ & $\begin{array}{l}\text { Measure how } \\
\text { close forecasts } \\
\text { or prediction are } \\
\text { to eventual } \\
\text { outcomes }\end{array}$ \\
\hline
\end{tabular}

\section{MATHEMATICAL RESULTS}

The experimental setup in execution is shown in Fig1.

The graph of actual exchange rate and forecasted values is shown in Fig2.

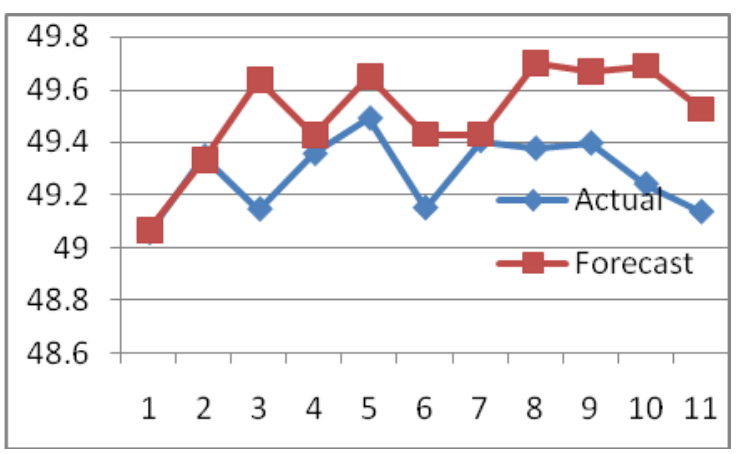

Fig1. Program in execution

The Mean Absolute Error and Normalized Mean square error are calculated as $\mathbf{0 . 2 2 8 0 0 9}$ and $\mathbf{0 . 0 8 2 0 8}$.

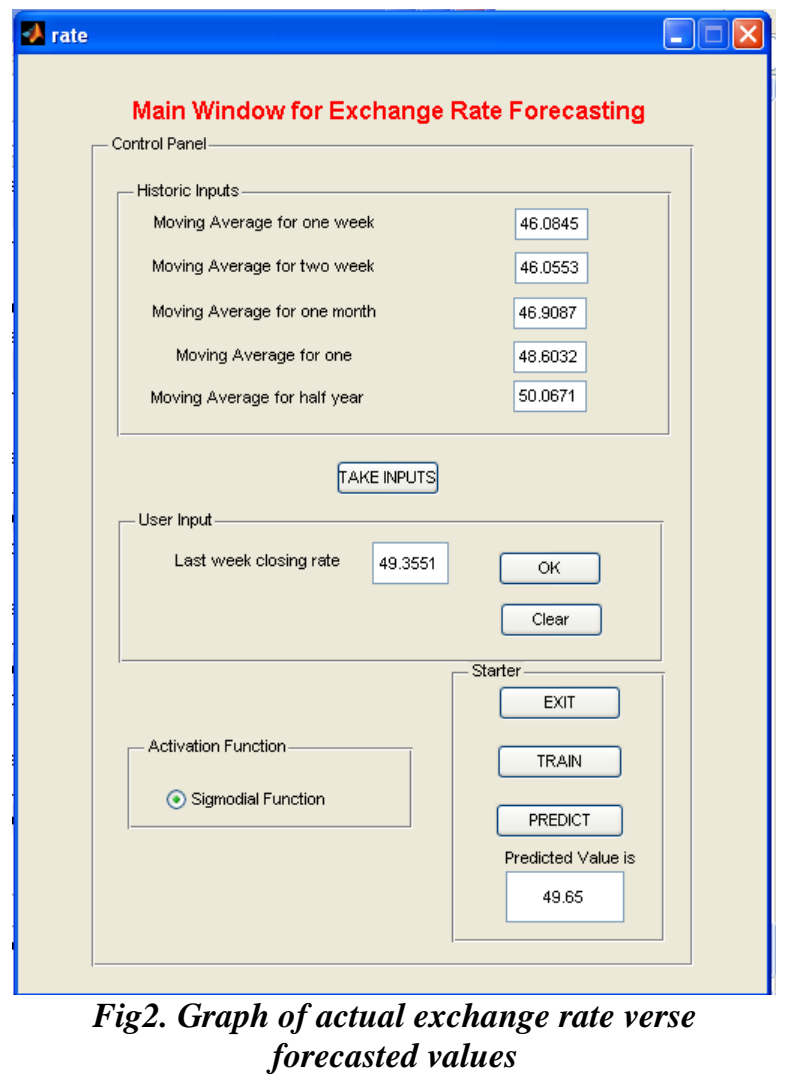

\section{CONCLUSION}

The mean absolute error (MAE) is a quantity used to measure how close forecasts or predictions are to the eventual outcomes. In this case it is less than .5. The NMSE (Normalized Mean Square Error) is an estimator of the overall deviations between predicted and measured values. In this case it is less than .1. From the mathematical results it is concluded that ANN is a good forecaster in exchange rate forecasting. 


\section{FUTURE SCOPE}

In this experimental setup we only forecast USD in term of Indian rupee. We may also use this track for other types of exchange rates. Moreover in this experimental setup only the sigmodial Activation function is used. We can vary the activation function in term of Thresholding, Signum, or Hyperbolic and make a comparative analysis of their performance to select best activation function.

\section{REFERENCES}

[1] J. A. Anderson 1997., An Introduction to Neural Networks.

[2] Ritanjali Majhi Panda, G. Sahoo 2006, Efficient Prediction of Foreign Exchange Rate using Nonlinear Single Layer Artificial Neural Model, in IEEE Conference on Cybernetics and Intelligent Systems.

[3] Dr. Cem Kadilar, Dr. Muammer 2009, Forecasting The Exchange Rate Series With ANN: The Case Of Turkey, Istanbul University Econometrics and Statistics eJournal.

[4] Suresh Kumar Sharma, Vinod Sharma 2011, ANN Approach for Daily Prediction of Gas Load Forecasting, in 5th National Conf. Computing For Nation Development; INDIACom.

[5] Liliana, Togar Alam Napitupulu 2010, Artificial Neural Network Application in Gross Domestic Product Forecasting," in Proc. 2nd Int. Conf. on Advances in Computing, Control, and Telecommunication Technologies.
[6] Yong Wang Dawu Gu Jianping Xu Jing Li. 2009 , Back Propagation Neural Network for Short-term Electricity Load Forecasting with Weather Features , In 9th Int. Conf. On Computational Intelligence and Natural Computing.

[7] Armi S. Jovero, “ Forecasting and Its Applications," Thesis, Philippine Christian University.

[8] Joarder Kamruzzaman, Ruhul A Sarker. 2003. Forecasting of Currency Exchange Rates using ANN: A Case Study, in Proc. Int. Conf. On Neural Networks And Signal Processing, [9] Abdul Kalam Azad, Md. Mahsin 2011. Forecasting Exchange Rates of Bangladesh using ANN and ARIMA Models: A Comparative Study, in International Journal Of Advanced Engineering Sciences And Technologies.

[10] Ashok k. Nag, Amit Mitra 2002.,Forecasting Daily Foreign Exchange Rates Using Genetically Optimized Neural Networks, in Journal Of Forecasting.

[11] Joarder Kamruzzaman , Ruhul A Sarker Iftekhar Ahmad 2003,SVM Based Models for Predicting Foreign Currency Exchange Rates, in 3rd IEEE International Conf. on Data Mining.

[12] Joarder Kamruzzaman 2004., ANN-Based Forecasting of Foreign Currency Exchange Rates," in Neural Information Processing - Letters and Reviews.

[13] S. Rajasekaran ,G. A. Vijayalakshmi pai 2006.,Neural Networks, Fuzzy Logic, and Genetic Algorithms.

[14]. Yihang, Liu, Lieli,Liu 2006.,Sales forecasting through fuzzy neural networks, in Proc. International Conference on Electronic Computer Technology. 